\title{
Carcinoma de Células Claras Variedad No Hialinizante de Parótida: Comunicación de Dos Casos con Diferente Grado de Diferenciación
}

\author{
Non-Hyalinizing Clear Cell Carcinoma of the Parotid: \\ Report of Two Cases with Different Grade of Differentiation
}

Avila, R. E.; Samar, M. E.; Ferraris, L.; Ferraris, R. V.; Fonseca, I.; Corball, A.; Asís, O. G. \& Olmedo, L.

\begin{abstract}
AVILA, R. E.; SAMAR, M. E.; FERRARIS, L.; FERRARIS, R. V.; FONSECA, I.; CORBALL, A.; ASÍS, O. G. \& OLMEDO, L. Carcinoma de células claras variedad no hialinizante de parótida: comunicación de dos casos con diferente grado de diferenciación. Int. J. Morphol., 31(3):1056-1061, 2013.
\end{abstract}

RESUMEN: El carcinoma de células claras es una neoplasia rara de bajo grado que se desarrolla casi exclusivamente en glándulas salivales menores humanas. El objetivo de esta comunicación es analizar las características estructurales, histoquímicas e inmunohistoquímicas (IHQ) de dos casos de carcinoma de células claras de parótida y realizar el diagnóstico diferencial con otros tumores salivales primarios y metastásicos que presentan células claras. Cortes de ambos tumores fueron procesados para $\mathrm{H} / \mathrm{E}$, tricrómicos de Masson y Dane, Azul de toluidina, Azul alciano, PAS y PAS/diastasa; marcaciones IHQ para citoqueratinas de bajo y alto peso molecular, ki67, HMB45, p63 y proteína S-100. El patrón estructural de estos tumores estaba determinado por nidos y cordones de células claras delimitados por un estroma no hialinizado. En un tumor se observó una neoplasia maligna a células claras con manifiesta anaplasia. La expresión de ki67 fue importante. El otro tumor estaba constituido por células claras monomorfas sin signos manifiestos de atipia y casi nula expresión de ki67. Con PAS se demostró la presencia de glucógeno y no se observó un desarrollo importante del estroma colágeno en ambas neoplasias. En ambos casos resultó francamente positiva la inmunomarcación para citoqueratinas de bajo y alto peso molecular. Por el contrario resultó negativa para HMB45 y p63. La proteína S-100 tuvo su expresión en células aisladas. Se concluye que los casos presentados son de localización poco común (parótida) según lo descripto en la bibliografía; corresponden a la variedad no hialinizante ya que no está presente un importante estroma colágeno hialinizado, y ambos tumores son primarios de glándulas salivales, de origen epitelial, no melanocítico ni hematopoyético (linfomas) como lo demuestran las marcaciones IHQ.

PALABRAS CLAVE: Parótida; Carcinoma de células claras; Inmunohistoquímica; Diagnóstico diferencial.

\section{INTRODUCCIÓN}

Los tumores de células claras de cabeza y cuello son entidades nosológicas raras (Said-Al Naief \& Klein, 2008). En este grupo se encuentra el carcinoma de células claras (CCC), neoplasia de bajo grado de malignidad, localmente infiltrante, que corresponde a menos del $1 \%$ de todos los tumores epiteliales de glándulas salivales, descrito por primera por Milchgrub et al. (1994).

El CCC es una de las nuevas entidades incorporadas en la actual clasificación de tumores de glándulas salivales de la OMS (Ellis \& Auclair, 2008; Samar et al., 2009; Soriano González et al., 2010). Ellis \& Auclair lo definen como una neoplasia epitelial maligna con una población monomorfa de células con citoplasma ópticamente claro con Hematoxilina/eosina y un estroma colágeno hialinizado no siempre presente en todos los tumores; la microscopía electrónica y la inmunohistoquímica demuestran la ausencia de células mioepiteliales. Por ello, se postula que esta patología deriva de las células epiteliales ductales (Ellis \& Auclair). Se desarrolla casi exclusivamente en glándulas salivales menores (paladar y lengua) y raramente en glándula parótida, con mayor frecuencia en mujeres adultas (Batzakis et al., 1994; Ellis \& Auclair; Chatelain et al., 2011; Kauzman et al., 2011). 
AVILA, R. E.; SAMAR, M. E.; FERRARIS, L.; FERRARIS, R. V.; FONSECA, I.; CORBALL, A.; ASíS, O. G. \& OLMEDO, L. Carcinoma de células claras variedad no hialinizante de parótida: comunicación de dos casos con diferente grado de diferenciación. Int. J. Morphol., 31(3):1056-1061, 2013.

Su diagnóstico diferencial con otros tumores epiteliales de glándulas salivales con células claras comprende un espectro de posibilidades tales como los carcinomas epitelial/mioepitelial, oncocítico, mucoepidermoide y mioepitelial, oncocitoma, mioepitelioma, entre otros (Wang et al., 2002). También se deben considerar los tumores metastásicos como ocurre con el carcinoma de origen renal y el melanoma (Wang et al.).

El objetivo de este reporte fue analizar las características estructurales, histoquímicas e inmunohistoquímicas (IHQ) de 2 casos de CCC desarrollados en la glándula parótida humana y realizar el diagnóstico diferencial con otros tipos de tumores salivales primarios y metastásicos que presentan una población de células claras.

\section{MATERIAL Y METODO}

Caso clínico 1. Hombre de de 75 años que presentó una tumoración en región parotídea derecha, de un año de evolución, bien delimitada, dura, no adherida a estructuras adyacentes, con un tamaño aproximado de $4,5 \mathrm{~cm}$. El paciente manifestó dolor leve espontáneo que se incrementaba con la palpación. Se procedió a la exéresis quirúrgica del tumor y nódulos linfáticos regionales.

Caso clínico 2. Mujer de 50 años que consulta por tumoración en región parotídea izquierda de 6 meses de evolución, con un diámetro de 1,5 cm aproximadamente; bien delimitada, de consistencia firme y no adherida a planos superficiales ni profundos.

En ambos casos, los cortes histológicos tumorales fueron procesados para las tinciones de $\mathrm{H}$-E, tricrómicos de Masson y Dane, Azul de toluidina pH 3,8, Azul de alcián ( $\mathrm{pH} 2,5$ y 1,0), PAS y PAS/diastasa. Además, se realizó marcación inmunohistoquímica para citoqueratinas de bajo y alto peso molecular, ki67, HMB45, proteína S-100 y p63 (Samar et al., 2004).

\section{RESULTADOS}

El patrón estructural de ambos tumores mostraba nidos, cordones y láminas de células de citoplasma claro delimitados por un estroma colágeno no hialinizado, como se pudo apreciar con la coloración tricrómica de Masson.

Caso 1. Macroscopía: Losange de piel de 7 x $3 \mathrm{~cm}$ con abundante tejido celular subcutáneo. Al corte se reconoció una lesión tumoral de 4 × 4 × $3 \mathrm{~cm}$, con márgenes infiltrantes, color blanquecino y consistencia indurada. Los límites quirúrgicos profundos y superficiales colindaban con el tumor; trozo de tejido adiposo del que se

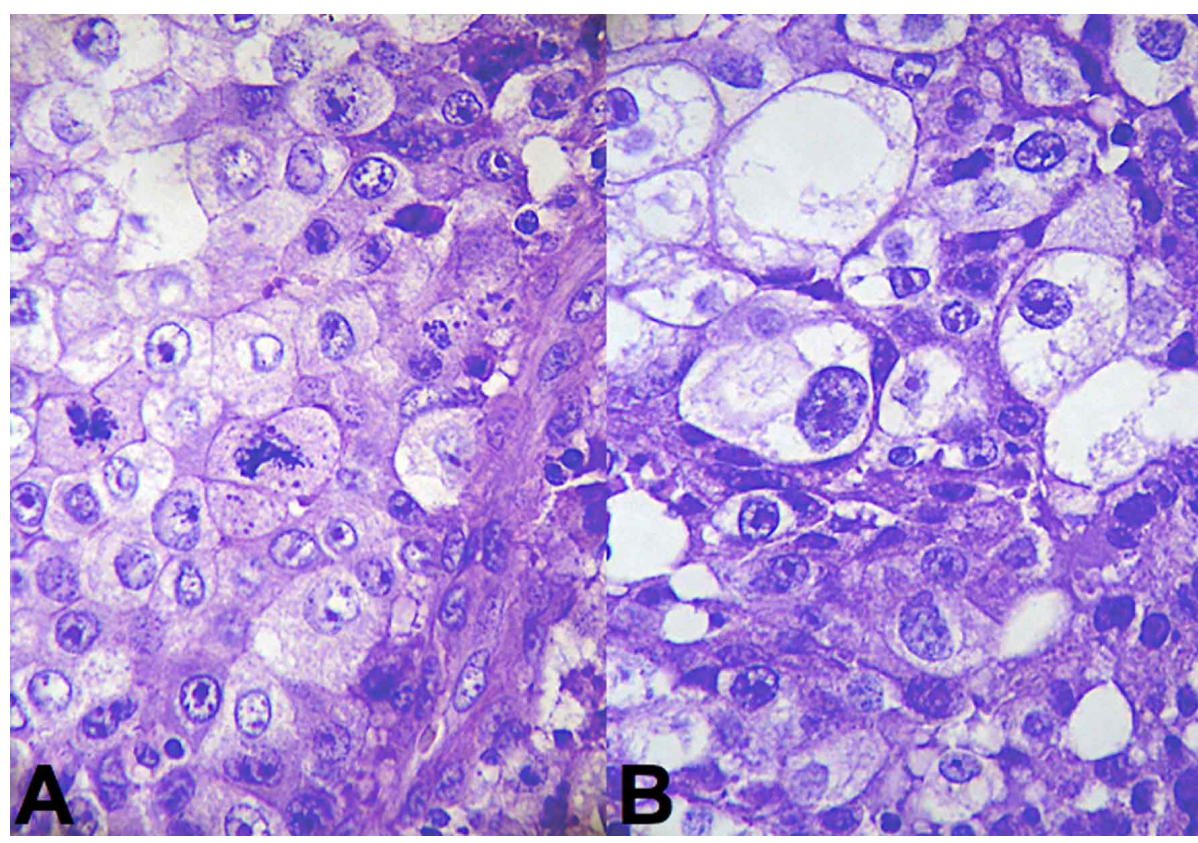

Fig. 1. Carcinoma de células claras anaplásico. A. Las células muestran pleomorfismo, variaciones de forma y tamaño del núcleo y del citoplasma, alteración de la relación núcleo/citoplasma, hipercromasia nuclear, nucléolos prominentes, células y núcleos gigantes, mitosis atípicas. H/E. 400x. B. Metástasis en linfonodo regional. H/E. 400x. aislaron 5 nódulos linfáticos que al corte tenían color pardo y consistencia firme.

Microscopía: con $\mathrm{H} / \mathrm{E}$ los cortes mostraron una neoplasia de estirpe epitelial, constituida por una población monomorfa de células claras redondeadas o poliédricas, con manifiesta anaplasia, pleomorfismo con variaciones de forma y tamaño del núcleo y del citoplasma, relación núcleo/citoplasma alterada, hipercromasia nuclear y nucleolos bien evidentes, algunos gigantes. Las mitosis atípicas eran numerosas (Fig. 1A). Con la coloración de PAS y PAS/ diastasa se comprobó la presencia de inclusiones de glucógeno. No se observaron mucinas con las tinciones tricrómico de Dane, Azul de toluidina y Azul alcián. 
AVILA, R. E.; SAMAR, M. E.; FERRARIS, L.; FERRARIS, R. V.; FONSECA, I.; CORBALL, A.; ASÍS, O. G. \& OLMEDO, L. Carcinoma de células claras variedad no hialinizante de parótida: comunicación de dos casos con diferente grado de diferenciación. Int. J. Morphol., 31(3): 1056-1061, 2013.

En algunas áreas se desarrolló un infiltrado inflamatorio difuso, focos de metaplasia escamosa y compromiso perineural. De los 5 nódulos linfáticos estudiados, 3 presentaron compromiso metastásico del tumor descrito (Fig. 1B).

La inmunomarcación nuclear mostró una importante expresión de ki67 (aproximadamente de un 40\%), indi- cando un alto índice de proliferación celular (Fig. 2A). También fue positiva la inmunohistoquímica para citoqueratinas de bajo y alto peso molecular y negativa para HMB45 (Fig. 2B). La negatividad para p63 demostró la falta de diferenciación mioepitelial. La proteína S-100 tuvo expresión sólo en células aisladas.

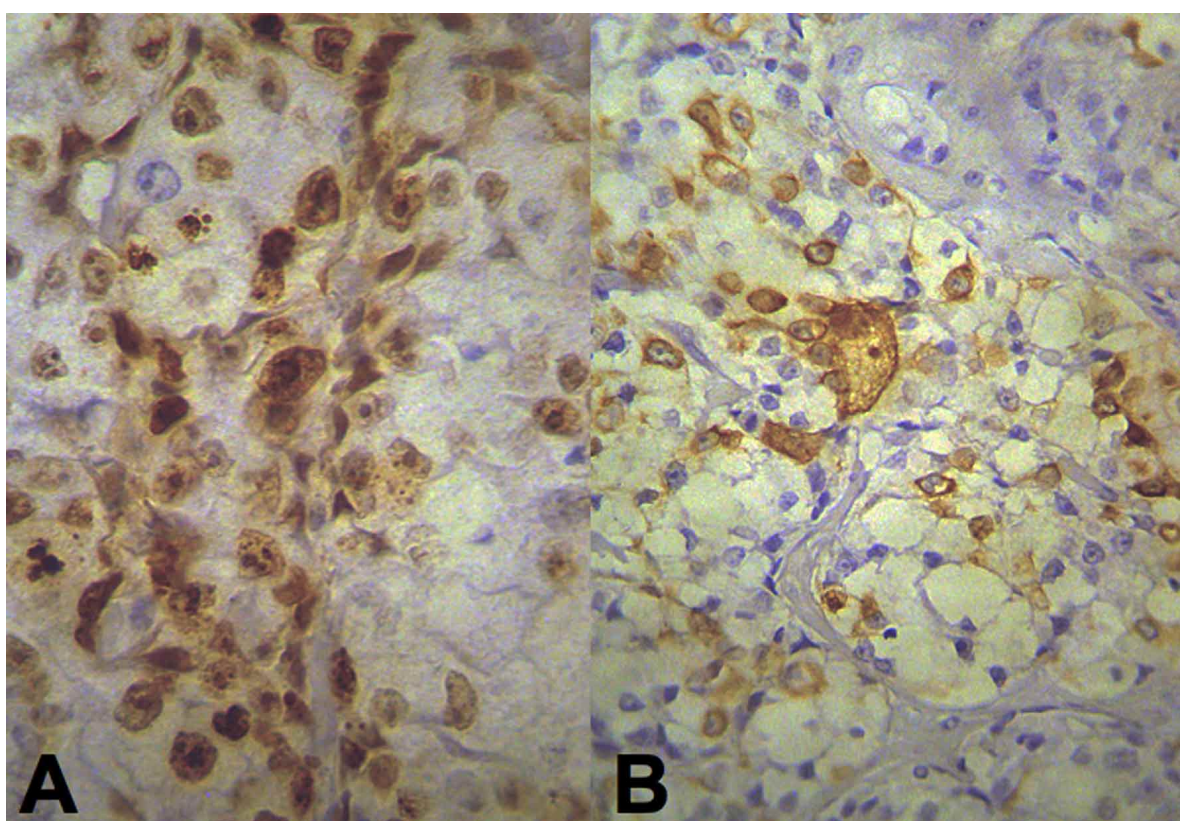

Fig. 2. Carcinoma de células claras anaplásico. A: Inmunohistoquímica. Marcación positiva para ki67. 400x. B. Inmunohistoquímica. Marcación positiva para citoqueratinas. 400x.

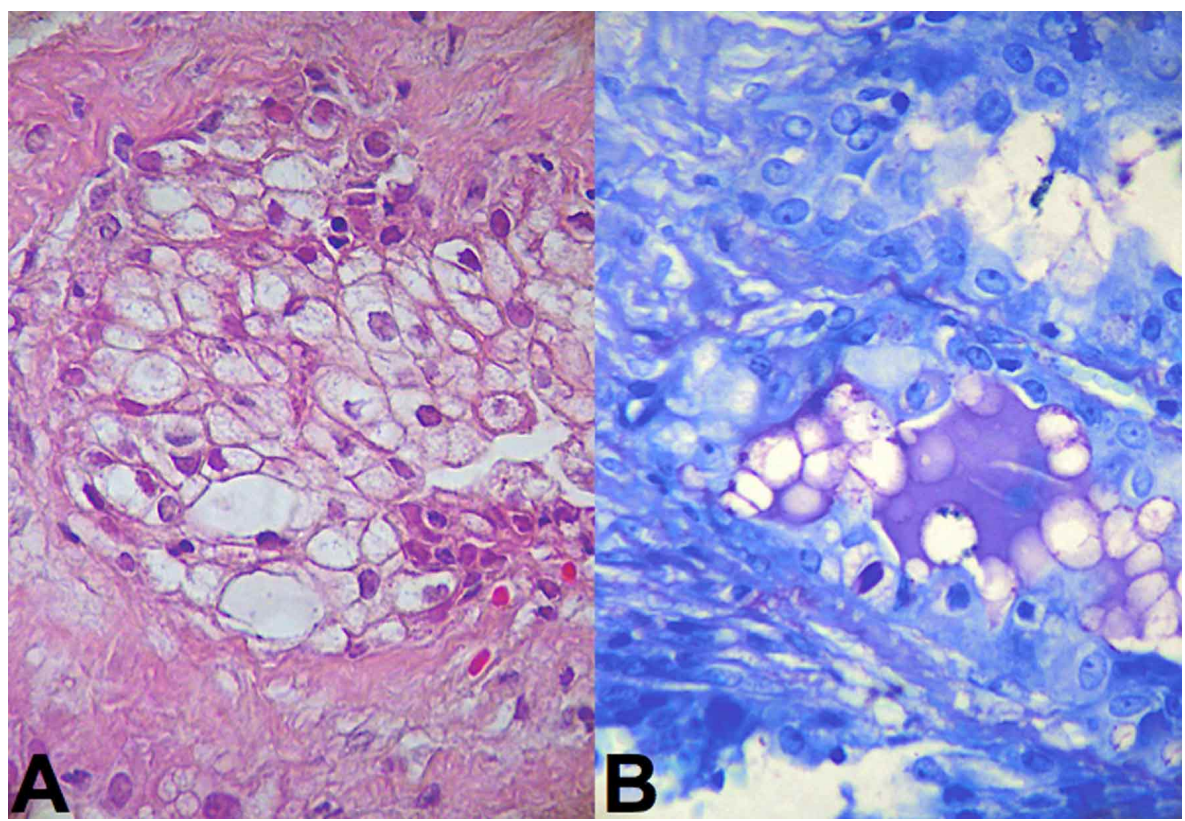

Fig. 3. Carcinoma de células claras diferenciado. A. Tumor constituido por células claras monomorfas sin signos de atipia. H/E. 400x. B. Grupos celulares aislados coloreados con Azul de toluidina $\mathrm{pH} 3,8$. 400x.
Caso 2. Macroscopía: Se analizaron 2 trozos del material proveniente de la cirugía. Un trozo de tejido correspondiente al tumor localizado en parótida izquierda, de $1 \times 1 \times 0.5 \mathrm{~cm}$. Al corte tenía color pardo y consistencia elástica. Parótida, lóbulo superficial; trozo de tejido de superficie polilobulada, color amarillento y consistencia elástica al corte. No se observó tumor macroscópicamente evidente. Nódulo linfático de $2 \times 1 \times 0.5 \mathrm{~cm}$, color pardo grisáceo al corte y de consistencia elástica.

Microscopía: con H-E se observó un tumor constituido por células claras monomorfas sin signos de atipia y casi nula expresión de ki67 (Fig. 3A). Inclusiones de glucógeno PAS positivo ocupaban el citoplasma de las células claras. Grupos celulares aislados se colorearon con Azul alciano y Azul de toluidina (Fig 3B).

La inmunomarcación fue francamente positiva para citoqueratinas de bajo y alto peso molecular. Por el contrario resultó negativa para HMB45, proteína S-100 y p63. Los cortes histológicos del nódulo linfático mostraron su arquitectura general conservada y grandes folículos linfoides con centros germinativos reactivos. Había un incremento del infiltrado linfomonocitario y polimorfonucleares neutrófilos en cortical y medular, con dilatación de los senos linfáticos, congestión vascular y edema. No se observó malignidad ni lesiones específicas. 


\section{DISCUSIÓN}

Describimos dos casos infrecuentes de CCC no hialinizante originados en glándula parótida. Sus características estructurales, histoquímicas e inmunohistoquímicas nos permiten diferenciarlo de otros tumores con células claras. La PAS positividad de los citoplasmas se relaciona con un contenido significativo de glucógeno (Ponniah et al., 2007). Además, sus células son inmunorreactivas para citoqueratinas de bajo y alto peso molecular y negativas para p63 y HMB45. Con S-100 sólo se observa una tinción positiva en células aisladas del CCC tipo anaplásico. Estos resultados coinciden con lo descrito en la literatura (Ellis \& Auclair).

Considerando que el crecimiento de los tumores malignos es muy variable y probablemente revela su curso clínico, se estudió la expresión del marcador de proliferación celular ki67 para comparar el caso 1 -CCC anaplásicocon el caso 2 - CCC del mismo histotipo pero con un alto grado de diferenciación celular -. Se comprobó que las características celulares de anaplasia se asocian a una importante actividad proliferativa medida con el anticuerpo ki67 (Scholsen \& Gerdes, 2000; Triantafillidou et al., 2006).

Por otro lado, las células claras están presentes en un grupo heterogéneo de tumores de glándulas salivales, cuyo correcto diagnóstico es un verdadero desafío tanto para especialistas de cabeza y cuello como para patólogos, clínicos y estomatólogos. La importancia del diagnóstico diferencial del CCC de glándulas salivales con otros tumores más agresivos con células claras como el carcinoma mucoepidermoide, carcinoma epitelial/mioepitelial, el adenocarcinoma de células acinares y tumores metastáticos como el carcinoma renal de células claras y el melanoma, radica en su tratamiento y pronóstico adecuados (Angiero \& Stefani, 2007; Ellis \& Auclair; O’Sullivan-Mejía et al., 2009).

El carcinoma mucoepidermoide es un tumor epitelial maligno con proporciones variables de células mucosas, epidermoides, intermedias, columnares, claras y ocasionalmente células oncocíticas; su comportamiento biológico se relaciona con el grado histológico tumoral. Si bien las células claras también presentan glucógeno, son características de esta neoplasia las células epidermoides y las células mucosas secretoras de mucinas PAS positivas, alcianofílicas y metacromáticas que lo diferencian del CCC (Avila et al., 2011; Samar et al., 2011). En cuanto al adenocarcinoma de células acinares, es un tumor epitelial maligno, donde se observan células neoplásicas con diferenciación predomi- nante tipo serosa, semejantes a las células serosas normales. En ocasiones se encuentran células vacuoladas, semejantes a las células ductales, células no específicas glandulares y células claras glucógeno negativas, a diferencia del CCC. Según Ellis \& Auclair, este carcinoma es el segundo más común dentro de las neoplasias malignas de glándulas salivales. Se localiza en la glándula parótida en el $80 \%$ de los casos. Sus patrones de crecimiento de tipo sólido o lobular, microquístico, papilar, quístico o folicular no se observan en el CCC (Samar et al., 2011).

El carcinoma epitelial/mioepitelial es un tumor epitelial maligno bifásico de bajo grado. Su estructura histológica muestra formaciones ductales revestidas por una doble capa de células, interna de células epiteliales y externa de células mioepiteliales, con células claras ricas en glucógeno. El CCC no presenta diferenciación mioepitelial lo que facilita su diagnóstico (Samar et al., 2010).

El oncocitoma es un tumor benigno constituido por células epiteliales grandes, los oncocitos o células oxífilas, de forma poligonal con citoplasma granular eosinofílico debido a la presencia de abundantes mitocondrias atípicas; la eosinofilia variable de su citoplasma permite clasificarlas en células claras con glucógeno y células oscuras granulares eosinófilas que confirman su diagnóstico (Ellis \& Auclair). Todos los oncocitomas, incluyendo la variante a células claras, se colorean con ácido fosfotúngstico/hematoxilina (PTH) a diferencia del CCC (Ellis \& Auclair).

También se debe tener en cuenta al adenoma sebáceo y su contraparte maligna, el adenocarcinoma sebáceo, cuyas células débilmente coloreadas, los sebocitos, presentan un citoplasma espumoso con contenido lipídico y nada de glucógeno. Los lípidos se pueden identificar en cortes por congelación con coloraciones específicas como son los diferentes Sudanes (Samar et al., 2004, 2011).

Los mioepiteliomas son una forma muy rara de tumor de glándulas salivales, que corresponde a menos del $1 \%$ de todos los tumores de estos órganos, localizado más frecuentemente en parótida (40\%) y paladar duro. Compuesto totalmente por células mioepiteliales, sin formaciones ductales, fue considerado como un subtipo de adenoma pleomorfo hasta 1991, fecha en que la Organización Mundial de la Salud lo clasificó como una entidad independiente. Junto al carcinoma mioepitelial, caracterizado por su crecimiento infiltrativo y una arquitectura nodular con periferia hipercelular, mitosis y áreas de necrosis, suelen presen- 
tar una población de células mioepiteliales modificadas, que pueden ser fusiformes, plasmocitoides, epitelioides o claras que se observan con distribución y cantidad diferentes de acuerdo a la variedad tumoral de que se trate. La inmunohistoquímica es positiva para las células claras de estos tumores (alfa-SMA, p63) y negativa para células claras del CCC (Avila et al., 2008; Samar et al., 2011).

Si bien las lesiones metastásicas de la cavidad oral son muy raras, el carcinoma renal de células claras es una neoplasia que puede dar siembras en la región de cabeza y cuello, afectando senos paranasales, lengua, laringe, mandíbula, hueso temporal, tiroides y parótida (Will et al., 2008). Cuando compromete la glándula parótida la diferenciación entre tumores a células claras de glándulas salivales y metástasis de cáncer renal suele resultar difícil con las técnicas histológicas de rutina. Por el contrario, la inmunomarcación para citoqueratinas contribuye en el diagnóstico ya que es focalizada en la metástasis renal y difusa en el CCC de glándulas salivales, como se pudo observar en nuestra casuística (Marioni et al., 2004). Otras características de la metástasis renal, no observadas en nuestras muestras, son su arquitectura heterogénea y la presencia de una red vascular sinusoidal prominente acompañada de hemorragias y depósitos de hemosiderina. La presencia de lípidos intracitoplasmáticos en células claras renales requiere para su identificación exámenes en tejidos congelados (Ponniah et al.).
El examen clínico de nuestros pacientes y estudios imagenológicos complementarios corroboraron la ausencia de patología renal detectable.

Otra neoplasia que puede dar metástasis en parótida es el melanoma, neoplasia con diferentes tipos de células como las claras, epitelioides, oncocitoides, plasmocitoides (Acosta et al., 2009; Huguet et al., 2010). En su diagnóstico son útiles los marcadores HMB45, Melan-A y la proteína S-100, altamente sensible (95\%). HMB45 resultó negativo en los CCC estudiados por nosotros y S-100 sólo dio una marcación aislada en el Caso 1 (Zubovits et al., 2009; Elshenaway et al., 2011.)

Se descartó, además, metástasis de linfoma a células B variante células claras y de linfoma anaplásico de células grandes, tumores citoqueratinas negativos (Shi et al., 2002; Manxhuka-Kerliu et al., 2011).

En conclusión, los casos presentados son de localización poco común (parótida) según lo descripto en la literatura, y corresponden a la variedad no hialinizante ya que no está presente un importante estroma colágeno hialinizado. Además, ambos tumores son primarios de glándulas salivales, de origen epitelial, no melanocítico ni hematopoyético (linfomas) o renal como lo demuestran las marcaciones IHQ y las características histopatológicas.

AVILA, R. E.; SAMAR, M. E.; FERRARIS, L.; FERRARIS, R. V.; FONSECA, I.; CORBALL, A.; ASÍS, O. G. \& OLMEDO, L. Nonhyalinizing clear cell carcinoma of the parotid: report of two cases with different grade of differentiation. Int. J. Morphol., 31(3):1056-1061, 2013.

SUMMARY: The clear cell carcinoma is a rare neoplam of low level grade that develops almost exclusively in human minor salivary glands. The objective of this present work is to analyze the structural, histochemical and inmunohistochemical (IHQ) characteristics of two cases of parotid clear cell carcinoma and make a differential diagnosis with other primary and metastatic salivary tumors that clear cells show. Serial cuts of both tumors were processed for H/E, Masson and Dane trichromes, Toluidine blue, Alcian blue, PAS and PAS/diastase; IHQ marking of both high-and low-molecular weight cytokeratins, ki67, HMB45, p63 and S-100 protein. The structural pattern of these tumors were determined by nests and cords of clear cells delimited by a stroma non hyaline. In a tumor a malign neoplasia was observed in clear cells with anaplasia. The ki67 expression was important. The other tumor was constitued of clear monomorph cells without manifestation signs of atypia and almost no ki67 expression. With PAS was confirmed the presence of glycogen and not observed an important development of the collagen stroma in both neoplasms. Both cases resulted very positive the immunostaining of both high and low molecular weight cytokeratins. It resulted negative for the HMB45 and p63. The protein S-100 has it's expression in isolated cells. We conclude that: the presented cases are very uncommon localization (parotid) as described by the literature; it matches a non hyalinizing variety because a very important hyalinized collagen stroma is not present, both primary tumors of salivary glands, of epithelial origin, non melanocytic, renal or hematopoietic lymphomas which shows immunostaining IHQ.

KEY WORDS: Parotid; Clear cells carcinoma; Immunohistochemistry; Differential diagnosis.

\section{REFERENCIAS BIBLIOGRAFICAS}

Acosta, A. E.; Fierro, E.; Velázquez, V. E. \& Rueda, X. Melanoma: patogénesis, clínica e histopatología. Rev. Asoc. Colomb. Dermatol. Cir. Dermatol., 17(2):87-108, 2009.
Angiero, F. \& Stefani, M. Hyalinizing clear cell carcinoma arising on the anterior palatoglossal arch. Anticancer Res., 27(6C):4271-7, 2007. 
AVILA, R. E.; SAMAR, M. E.; FERRARIS, L.; FERRARIS, R. V.; FONSECA, I.; CORBALL, A.; ASíS, O. G. \& OLMEDO, L. Carcinoma de células claras variedad no hialinizante de parótida: comunicación de dos casos con diferente grado de diferenciación. Int. J. Morphol., 31(3):1056-1061, 2013.

Avila, R. E.; Samar, M. E.; Fonseca, I. \& Ferraris, R. Mioepitelioma de parótida: estudio histológico, histoquímico e inmunohistoquímico. Ini. Inv., 3:a4, 2008.

Avila, R. E.; Samar, M. E., Fonseca, I.; Olmedo, L. A.; Asís, O. G. \& Ferraris R. Mucoepidermoid carcinoma of salivary glands: histologic and inmunohistochemical prognostic factors. Int. J. Morphol., 29(2):455-62, 2011.

Batzakis, J. G.; el-Naggar, A. K. \& Luna, M. A. Hyalinizing clear cell carcinoma of the salivary origin. Ann. Otol. Rhinol. Laryngol., 103(9):746-8, 1994.

Chatelain, B.; Curlier, A.; Euvrard, D. E.; Vitte, F.; Ricbourg, B. \& Meyer, C. Hyalinizing clear cell carcinoma of the maxilla. Rev. Stomatol. Chir. Maxillofac., 112(3):183-6, 2011.

Ellis, G. L. \& Auclair, P. L. AFIP Atlas of tumor pathology. Tumors of the salivary glands. Washington D. C., Armed Forces Institute of Pathology (AFIP), 2008.

Elshenawy, Y.; Youngberg, G. \& Al-Abbadi, M. A. Unusual clinical presentation of cutaneous malignant melanoma metastatic to the parotid gland; initially discovered by fine needle aspiration: case report and review of the literature. Diagn. Cytopathol., 39(5):3736, 2011.

Huguet, P.; Gabaldón, M. A.; Sansano, I.; Semidey, M. E.; Tallada, N.; Castelln, J.; et al. Melanoma maligno amelanótico en un ganglio de glándula parótida. Estudio clínicopatológico, inmunohistoquímico y molecular de un caso. Rev. Esp. Patol., 43(3):144-7, 2010.

Kauzman, A.; Tabet, J. C. \& Stiharu, T. I. Hyalinizing clear cell carcinoma: a case report and review of the literature. Oral Surg. Oral Med. Oral Pathol. Oral Radiol. Endod., 112(1):e26-34, 2011.

Manxhuka-Kerliu, S.; Petrusevska, G.; Kerliu, I.; Ahmeti, F.; DevolliDisha, E. \& Loxha, S.; et al. Clear cell variant of diffuse large Bcell lymphoma: a case report. J. Med. Case Rep., 5:182, 2011.

Marioni, G.; Galo, E.; Poletti, A.; Derosas, F. \& Staffieri, A. Uncommon metastatic site of renal adenocarcinoma: the oral tongue. Acta Otolaryngol., 124(2):197-201, 2004.

Milchgrub, S.; Gnepp, D. R.; Vuitch, F.; Delgado, R. \& AlboresSaavedra, J. Hyalinizing clear cell carcinoma of salivary gland. Am. J. Surg. Pathol., 18(1):74-82, 1994.

O’Sullivan-Mejia, E. D.; Massey, H. D.; Faquin, W. C. \& Powers, C. N. Hyalinizing clear cell carcinoma: report of eight cases and review of the literature. Head Neck Pathol., 3(3):179-85, 2009.

Ponniah, I.; SureshKumar, P. \& Karunakaran, K. Clear cell carcinoma of minor salivary gland--case report. Ann. Acad. Med. Singapore, 36(10):857-60, 2007.

Said-Al-Naief, N. \& Klein, M. J. Clear cell entities of the head and neck: a selective review of clear cell tumors of the salivary glands. Head Neck Pathol., 2(2):111-5, 2008.
Samar, M. E.; Avila, R. E.; Fonseca, I. \& Ferraris, R. Sebaceous epithelial/myoepithelial carcinoma of parotid: histopathological and immunohistochemical analysis. Int. J. Odontostomatol., 4(2):189-96, 2010

Samar, M. E.; Avila, R. E.; Fonseca. I.; Ferraris, R. V. \& Fernández, J. Tumores de glándulas salivales: aspectos histopatológicos y clínico-epidemiológicos. Córdoba, Ed. SeisC, 2009.

Samar, M. E.; Avila, R. E.; Asís, O. G. \& Fonseca, I. B. Glosario de histopatología: tumores epiteliales de glándulas salivales. Saarbrücken. Editorial Académica Española (EAE), 2011.

Samar, M. E.; Avila, R. E. \& Esteban Ruiz, F. Técnicas histológicas. Fundamentos y aplicaciones. Córdoba, SeisC, 2004.

Scholzen, T. \& Gerdes, J. The ki-67 protein: from the known and the unknown. J. Cell Physiol., 182(3):311-32, 2000.

Shi, Q.; Zhou, X.; Yan, X.; Xu, X.; Yin, H.; Zhong, T.; et al. Primary cutaneous CD30-positive anaplastic large cell lymphoma analysis. Chin. Med. J. (Engl.), 115(12):1802-5, 2002.

Soriano González, J.; Cano Valdéz, A. M. \& Sánchez Martínez, M. L. Carcinoma hialinizante de células claras de glándula salival. Experiencia en el Instituto Nacional de Cancerología de México. Patolog. Rev. Latinoam., 47(3):271, 2010.

Triantafillidou, K.; Dimitrakopoulos, J.; Iordanidis, F. \& Koufogiannis, D. Mucoepidermoid carcinoma of minor salivary glands: a clinical study of 16 cases and review of the literature. Oral Dis., 12(4):36470, 2006.

Wang, B.; Brandwein, M.; Gordon, R.; Robinson, R.; Urken, M. \& Zarbo, R. J. Primary salivary clear cell tumors, a diagnostic approach: a clinicopathologic and immunohistochemical study of 20 patients with clear cell carcinoma, clear cell myoepithelial carcinoma, and epithelial-myoepithelial carcinoma. Arch. Pathol. Lab. Med., 126(6):676-85, 2002.

Will, T. A.; Argarwall, N. \& Petruzzelli, G. J. Oral cavity metastasis of renal cell carcinoma: a case report. J. Med. Case Rep., 2:313, 2008.

Zubovits, J.; Buzney, E.; Yu, L. \& Duncan, L. M. HMB-45, S-100, NK1/C3, and MART-1 in metastatic melanoma. Hum. Pathol., 35(2):217-23, 2004.

Dirección para Correspondencia:

Rodolfo E. Ávila

Biología Celular, Histología y Embriología

Facultad de Ciencias Médicas

Histología y Embriología. Facultad de Odontología

Universidad Nacional de Córdoba

Córdoba

ARGENTINA

Recibido : 01-04-2012

Aceptado: 27-04-2013

Email: avilainfo@yahoo.com.ar 